\title{
Pengaruh Ketebalan Untuk White Cast Iron Low Chrome And Low Nikel Terhadap Kekerasan, Keausan, Serta Struktur Mikro Untuk Aplikasi Di Dalam Ball Grinding
}

\author{
SUMIRAT. U, Yusril, HERMAWAN. S \\ Pendidikan Teknik Mesin Universitas Pendidikan Indonesia Bandung, Indonesia \\ Teknik Mesin Institut Teknologi Nasional Bandung, Indonesia \\ Jl, Dr. Setiabudi No.229 Bandung 40154 \\ Jl. PHH. Mustafa No.23 Bandung 40124 \\ e-mail : sumiratuum@gmail.com
}

\begin{abstract}
ABSTRAK
Grinding Ball adalah salah satu komponen dalam mesin ball mill yang berfungsi untuk menggerus batuan mineral menjadi partikel yang sangat halus. Apabila grinding ball tersebut dapat dibuat di Indonesia, diharapkan harganya bisa lebih murah sehingga biaya produksi semen dapat diturunkan, harga semen lebih terjangkau, dan kesejahteraan rakyat dapat ditingkatkan. Tujuan dari penelitian ini adalah untuk mengembangkan prototype grinding ball pada ball mill sehingga dapat mensubtitusikan impor dari negeri serta dapat memproduksi sendiri di dalam negeri dan bersaing dengan produk impor. Pengembangan prototype grinding ball untuk aplikasi pada mesin ball mill menggunakan bahan material white cast iron dengan melalui proses pengecoran. Pengembangan ini bertujuan untuk mengetahui sifat material yang dalam hubunganya dengan sifat fisis dan mekanik melalui pengujian uji impak, kekerasan, serta struktur mikro. Hasil uji kekerasan menunjukan nilai kekerasan untuk spesimen uji keras 273,65 HB dan untuk spesimen uji impak 334,379 HB. Hasil uji impak menunjukan Harga impak 2,64 J/mm².
\end{abstract}

Kata Kunci : grinding ball, ballmill, white cast iron.

\begin{abstract}
Grinding Ball is one of the components in a ball mill machine that functions to grind mineral rock into very fine particles. If the grinding ball can be made in Indonesia, it is hoped that the price will be cheaper so that cement production costs can be lowered, cement prices are more affordable, and people's welfare can be increased. The purpose of this research is to develop a prototype grinding ball in a ball mill so that it can substitute foreign imports and can produce domestically and compete with imported products. The development of the grinding ball prototype for the ball mill machine application uses white cast iron material through a casting process. This development aims to determine the properties of the material in relation to physical and mechanical properties through impact, hardness, and microstructure tests. The hardness test results showed the hardness value for the hard test specimen 273,65 HB and for the impact test specimen 334,379 $\mathrm{HB}$. The impact test results show the impact price is 2,64 J/mm².
\end{abstract}

Keyword : grinding ball, ball mill, white cast iron 


\section{Pendahuluan}

Material logam yang memiliki unsur Fe sebagai pembentuk dasarnya dapat dibedakan menjadi baja dan besi cor. Baja merupakan logam yang terbentuk dari paduan unsur Fe dan unsur $\mathrm{C}$ (besi dari karbon), di mana fraksi maksimum dari unsur karbon di dalam baja adalah 2,1\% sedangkan besi cor adalah logam yang terbentuk dari paduan unsur besi $(\mathrm{Fe})$ dan unsur karbon (C) dimana kadar karbon (C) pada besi cor diatas 2,1\%. Karbon bebas dari baja akan membentuk karbida besi, sedangkan pada besi cor akan membentuk grafit yang memiliki sifat getas [2]. Namun tidak semua jenis besi cor memiliki grafit salah satunya besi cor putih (White Cast Iron), dimana besi cor putih tidak memiliki grafit dan sifatnya hampir sama dengan baja karbon tinggi. Di samping kedua unsur di atas, dalam baja terdapat pula unsur-unsur lain dalam jumlah kecil, seperti Mangan (Mn), Silicon (Si), Fosfor (P), Belerang (S). Dapat juga dipadu dengan unsur-unsur paduan seperti Chromium (Cr), Nikel (Ni), Wolfram (W), Molibden (Mo) dansebagainya, dan dapat divariasi menurut kebutuhan [3].

Grinding Ball adalah salah satu komponen dalam mesin ball mill yang berfungsi untuk menggerus batuan mineral menjadi partikel yang sangat halus. Grinding ball tersebut terbuat dari logam yang disyaratkan mempunyai karakteristik keras (tahan aus) sekaligus tangguh (tidak mudah pecah) dan tahan korosi untuk menanggung beban dan lingkungan selama proses penggilingan batuan. [5]

Material grinding ball memiliki persyaratan berupa nilai kekerasan yang tinggi serta ketahanan aus yang baik. Berdasarkan spesifikasi grinding ball menurut SNI-1069, material grinding ball yang terbuat dari material besi tuang dengan paduan krom tinggi memiliki kekerasan tertinggi sebesar $600 \mathrm{BHN} / 59$ HRC. [4]

Ketebalan dari suatu material dapat memberikan pengaruh terhadap perubahan harga kekerasan dan struktur mikronya. Pengaruh ketebalan besi cor terhadap harga kekerasannya adalah ketika terdapat perubahan ketebalan pada besi cor maka akan terjadi perubahan pada struktur mikro dan kekerasannya. Semakin tipis besi cor maka kekerasannya akan semakin tinggi karena besi cor yang tipis menghasilkan jumlah fasa perlit yang semakin banyak. [6].

\section{Metodologi Penelitian}

Penelitian ini dilakukan dengan metoda eksperimental, yaitu melalui pembuatan spesimen serta menerapkan beberapa pengujian terhadap spesimen tersebut untuk mendapatkan parameter yang diperlukan untuk melakukan analisa. Penelitian ini diawali dengan studi literatur, yang didapat dari jurnal penelitian yang terkait dengan Grinding ball. Berdasarkan studi literatur, kemudian dilakukan pengambilan sampel bahan grinding ball import dari India dan China sebagai bahan pembanding dalam penelitian ini. Bahan grinding ball ini selanjutnya diuji dengan uji spectrometer untuk mengetahui komposisi kimianya. Komposisi kimia dari material impor ini perlu diketahui untuk memastikan bahwa material tersebut masuk ke dalam kategori White cast Iron, yaitu memiliki kandungan karbon diatas 2,1\%. Disamping uji spectrometer, material impor ini juga diuji struktur mikro serta kekerasannya

Material yang menjadi objek dalam penelitian ini adalah bahan white cast iron hasil proses pengecoran sendiri. Pembuatan spesimen diawali dengan pemilihan bahan dan dilanjutkna dengan proses pengocoran untuk mendapatkan material white cast iron dengan komposisi $\mathrm{Cr}$ rendah. Spesimen ini kemudian diuji dengan beberapa pengujian, yaitu uji kekerasan, impak dan struktur mikro. Tujuan dari pengujian ini adalah untuk melihat karakteristik dari bahan white cast iron serta mengukur kelayakan bahan tersebut untuk diaplikasikan pada grinding ball mesin ball mill. Berdasarkan data hasil pengujian, dilakukan analisa dan menyimpulkan hasil dari pengujian material grinding ball. Kesimpulan yang didapatkan nantinya akan dijadikan sebagai acuan untuk melakukan proses produksi di dalam negeri. 


\subsection{Komposisi Kimia}

Penentuan komposisi kimia grinding ball ini dilakukan untuk membuat spesimen pengujian dengan membuat komposisi kimia yang nantinya dibandingkan dengan unsur kimia pada material grinding ball impor. Proses yang dilakukan untuk mengetahui kandungan komposisi yang terdapat pada material grinding ball impor adalah dengan cara pengujian uji spectrometer.

Pengujian spectrometer atau uji komposisi berfungsi untuk mengetahui komposisi yang terdapat pada material. Dari hasil pengujian spectrometer, diperoleh unsure-unsur kimia yang terdapat pada grinding ball impor yang berasal dari India yaitu :

Tabel 1. Komposisi Grinding ball India

\begin{tabular}{|c|c|}
\hline Unsur & Persentase komposisi (\%) \\
\hline $\mathrm{C}$ & 2,55 \\
\hline $\mathrm{Si}$ & 0,75 \\
\hline $\mathrm{S}$ & 0,013 \\
\hline $\mathrm{P}$ & 0,07 \\
\hline $\mathrm{Mn}$ & 0,1 \\
\hline $\mathrm{Ni}$ & 0,05 \\
\hline $\mathrm{Cr}$ & 16,17 \\
\hline
\end{tabular}

Setelah hasil komposisi diketahui maka data tersebut dapat dijadikan sebagai acuan untuk proses pengecoran spesimen yang nantinya dapat dijadikan bahan untuk pembuatan prototype grinding ball dengan cara menurunkan kadar komposisi kandungan $\mathrm{Cr}$ tersebut seperti pada tabel 1 dan tabel 2

Tabel 2. Unsur Kimia Komposisi 1

\begin{tabular}{|c|c|}
\hline Unsur & Persentase komposisi (\%) \\
\hline $\mathrm{C}$ & 2,1 \\
\hline $\mathrm{Si}$ & 0,7 \\
\hline $\mathrm{S}$ & 0,08 \\
\hline $\mathrm{P}$ & 0,07 \\
\hline $\mathrm{Mn}$ & 0,1 \\
\hline $\mathrm{Ni}$ & 1,5 \\
\hline $\mathrm{Cr}$ & 1,5 \\
\hline
\end{tabular}

Tabel 3. Unsur Kimia Komposisi 2

\begin{tabular}{|c|c|}
\hline Unsur & Persentase komposisi (\%) \\
\hline $\mathrm{C}$ & 3,2 \\
\hline $\mathrm{Si}$ & 0,8 \\
\hline $\mathrm{S}$ & 0,1 \\
\hline $\mathrm{P}$ & 0,07 \\
\hline $\mathrm{Mn}$ & 0,2 \\
\hline $\mathrm{Ni}$ & - \\
\hline $\mathrm{Cr}$ & 2,5 \\
\hline
\end{tabular}

\subsection{Pengujian Yang dilakukan}

a. Pengujian Kekerasan

Salah satu sifat mekanik material yang penting adalah kekerasan (Hardness). Uji kekerasan dengan menggunakan alat uji kekerasan Rockwell hardness tester (ASTM E-18), seperti yang terlihat pada gambar 1. Kekerasan menyatakan ketahanan suatu material terhadap deformasi plastis atau deformasi permanen pada permukaan, semakin tahan material tersebut terhadap 
deformasi plastis maka material tersebut semakin keras. Deformasi plastis adalah perubahan bentuk material secara permanen. Specimen uji keras terlihat pada gambar 2.

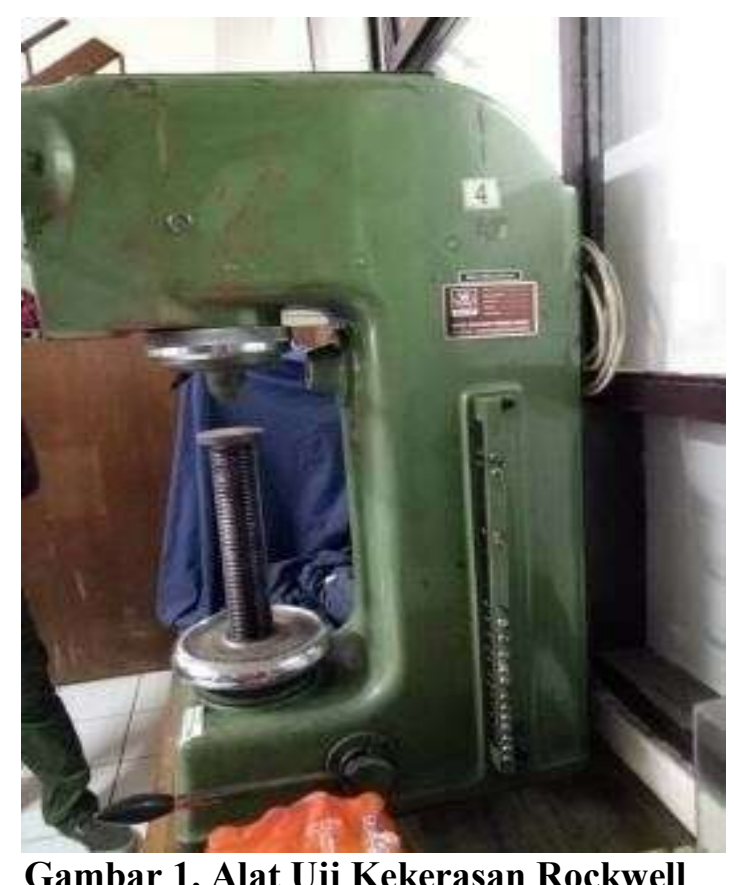

Gambar 1. Alat Uji Kekerasan Rockwell

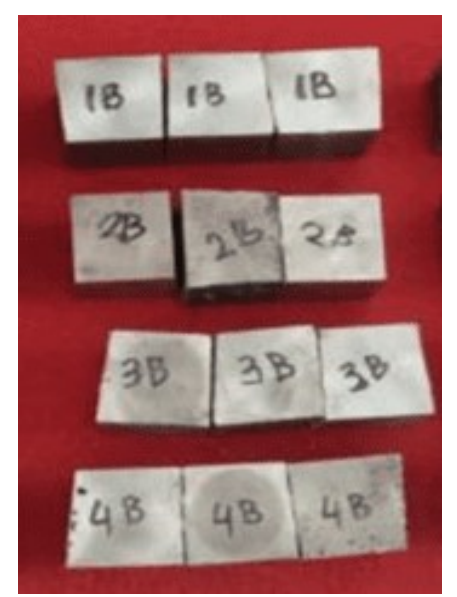

Gambar 2. Spesimen Uji Keras

b. Pengujian Uji Impak

Prinsip kerja uji impak yaitu benda kerja ditempatkan di bantalan/landasan untuk menerima pukulan dari massa yang bergerak (bandul) yang memiliki energi yang cukup untuk mematahkan spesimen. Dimana mesin harus mampu membaca energi yang diserap oleh spesimen sampai rusak. 
Logam dapat mengalami perubahan sifat dari ulet menjadi getas. Perubahan ini disebut dengan penggetasan (embrittlement). Gejala ini dapat diamati dari bentuk patahan yang berubah dari patah ulet menjadi patah getas dan juga bisa dilihat dari harga impak yang diperoleh. Faktor utama perubahan sifat ini disebabkan oleh konsentrasi tegangan, temperatur yang rendah, regangan yang rendah dan jenis material [1].

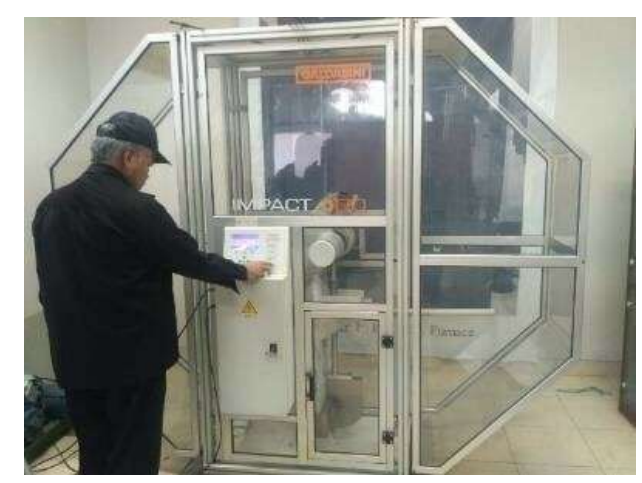

Gambar 3. Alat uji impak

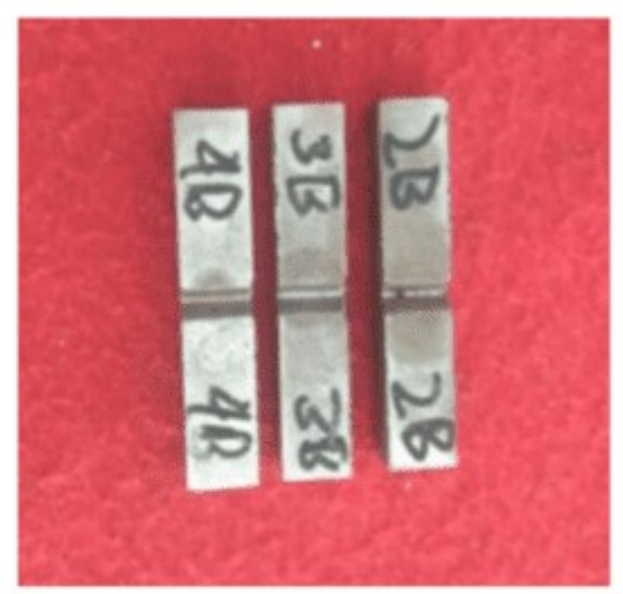

\section{Gambar 4. Spesimen Uji Impak}

Hasil dari proses pengecoran Y-block dipotong untuk dibuat spesimen untuk uji impak berdasarkan standar ASTM E-23. Mesin uji impak yang digunakan terliahta pada gambar 3 dan spesimen uji impak terlihat pada gambar 4

\section{c. Pengujian Analisis Struktur Mikro}

Pengujian struktur mikro dilakukan untuk mengetahui struktur mikro grinding ball, korelasinya dengan komposisi kimia serta kemungkinan proses heat treatment yang dilakukan. Pengujian struktur mikro dilakukan menggunakan mikroskop optik dengan berbagai perbesaran. Specimen untuk uji ASM terlihat pada gambar 5 sedangkan alat uji ASM terlihat pada gambar 6. 


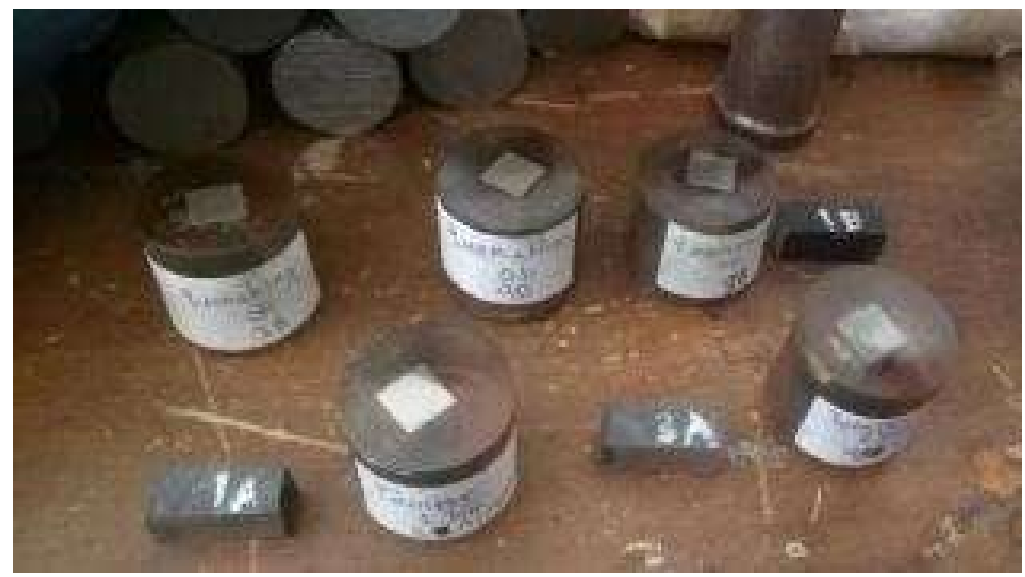

Gambar 5. Spesimen Uji ASM

Sebagaimanan umumnya analisa struktur mikro, specimen untuk melakukan analisa struktur mikro disiapkan dengan beberapa tahapan. Tahap pertama adalah mounting, yaitu pembingkaian spesimen dengan menggunakan resin. Specimen yang telah dibingkai selanjutnya digerinda dan diampelas agar didapatkan permukaan yang halus. Tahap selanjutnya adalah pemolesan yang bertujuan untuk menghilangakn goresan-goresan yang masih tersisa dari proses pengampelasan. Tahap akhir dari persiapan spesimen analisa struktur mikro adalah proses etsa, yaitu mereaksikan permukaan dengan larutan kimia tertentu agar muncul struktur mikro sehingga dapat diamati dengan mikroskop.

Analisa struktur mikro dilakukan dengan menggunkana mikroskop optik yang dilengkapi dengan kamera beserta satu roll film berwarna. Specimen uji diletakkan pada meja uji (anvil) pada posisi tegak lurus dengan lensa untuk mendapatkan gambar yang paling jelas dan akurat. Alat yang digunakan pada pengujian ASM ini adalah olympus metallurgical microscope dan olympus photomicrographic system, seperti yang terliaht pada gambar 6 .

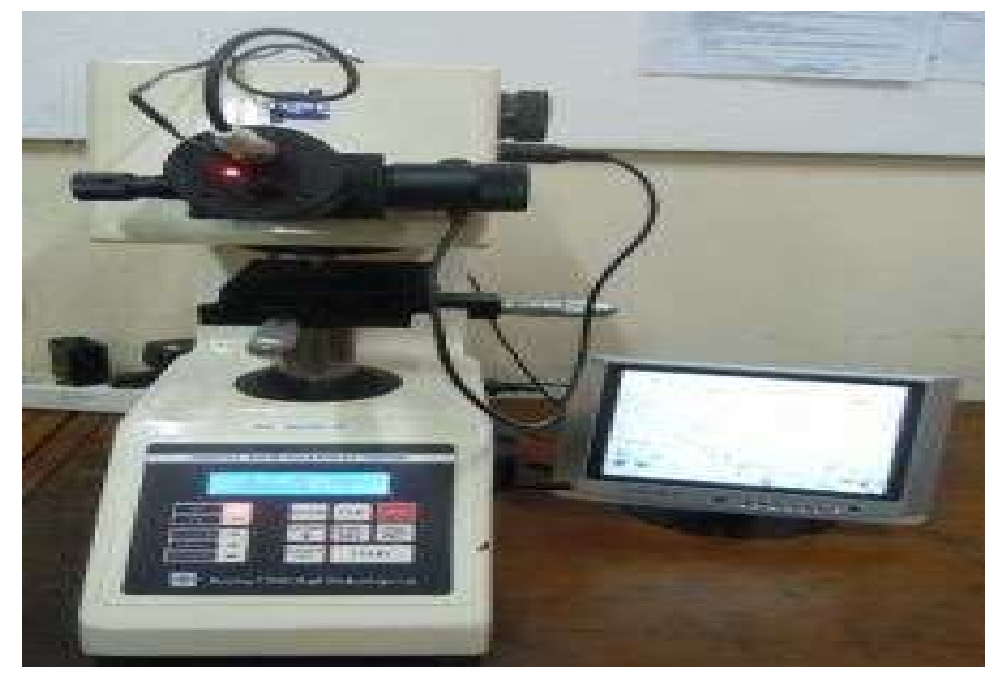

Gambar 6. Alat Uji ASM 


\section{Hasil dan Pembahasan}

\subsection{Hasil Pengujian Uji Kekerasan}

Pengujian Uji Kekerasan spesimen dilakukan untuk mengetahui kekerasan specimen hasil dari pengecoran sebagai dampak dari komposisi unsur kimia baru dan akan dibandingkan dengan material impor untuk mendapatkan hasil yang lebih optimal.

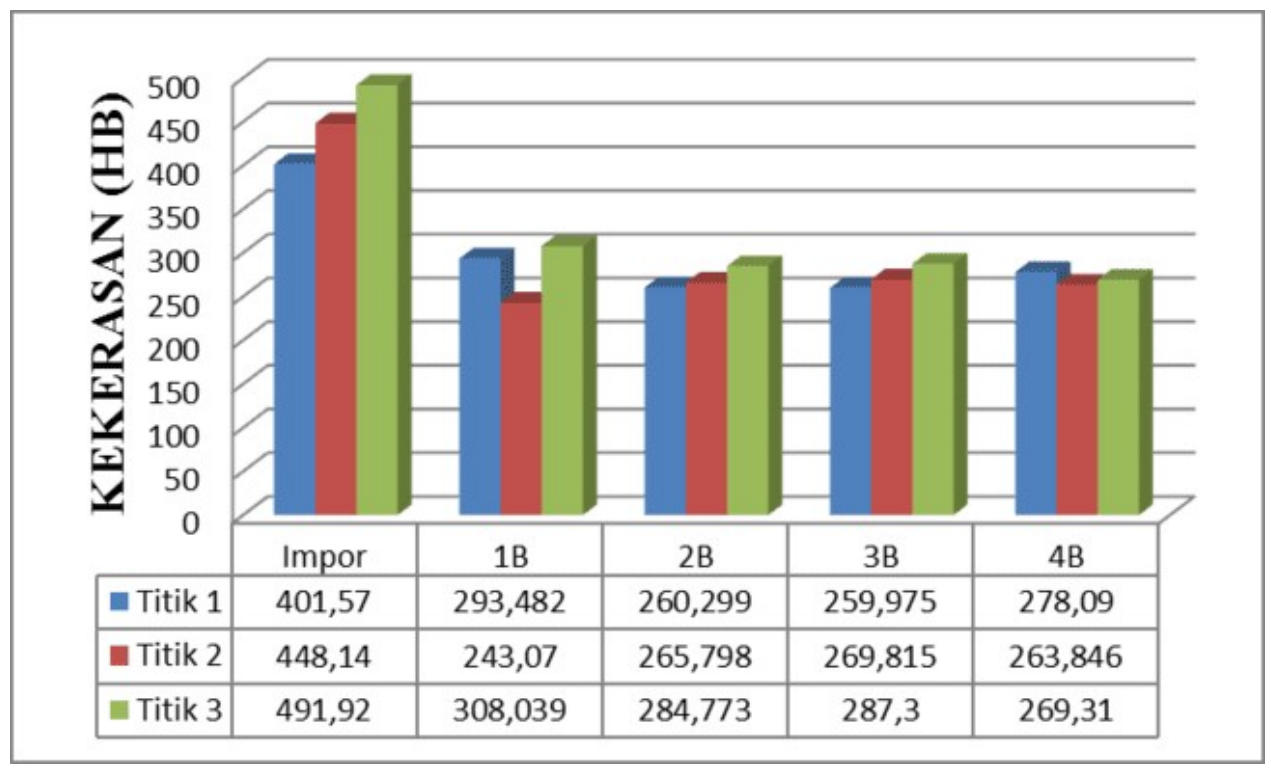

Gambar 7. Grafik Harga Kekerasan Tebal 30 mm VS Titik Spesimen

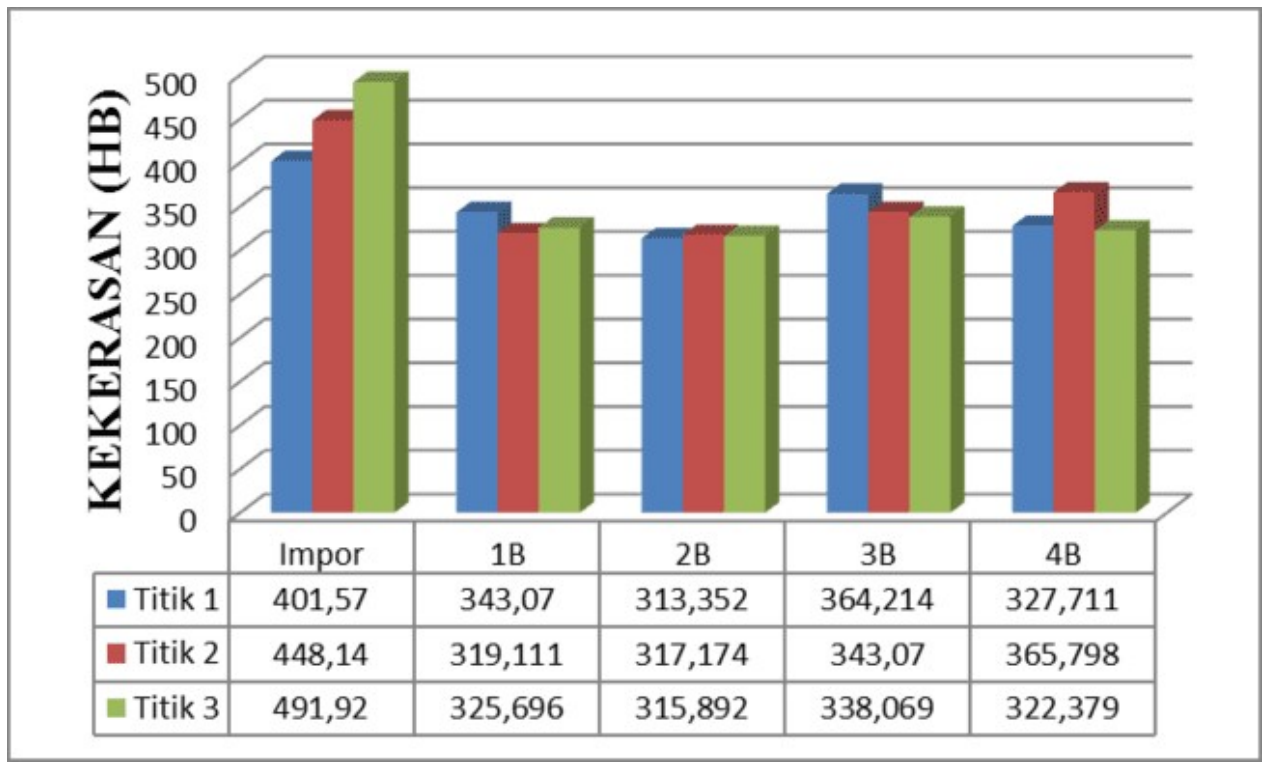

Gambar 8. Grafik Harga Kekerasan Tebal 10 mm VS Titik Spesimen

Gambar 7 dan gambar 8 memperlihatkan harga kekerasan dari hasil pengujina kekerasan pada spesimen dari bahan grinding ball impor dan spesimen dari hasil pengecoran dengan ketebalan $10 \mathrm{~mm}$ dan $30 \mathrm{~mm}$. Pengukuran kekerasan dilakukan pada 3 titik untuk setiap spesimen. . 
JURNAL REKAYASA ENERGI DAN MEKANIKA - Vol. 01 No. 01 (2021)

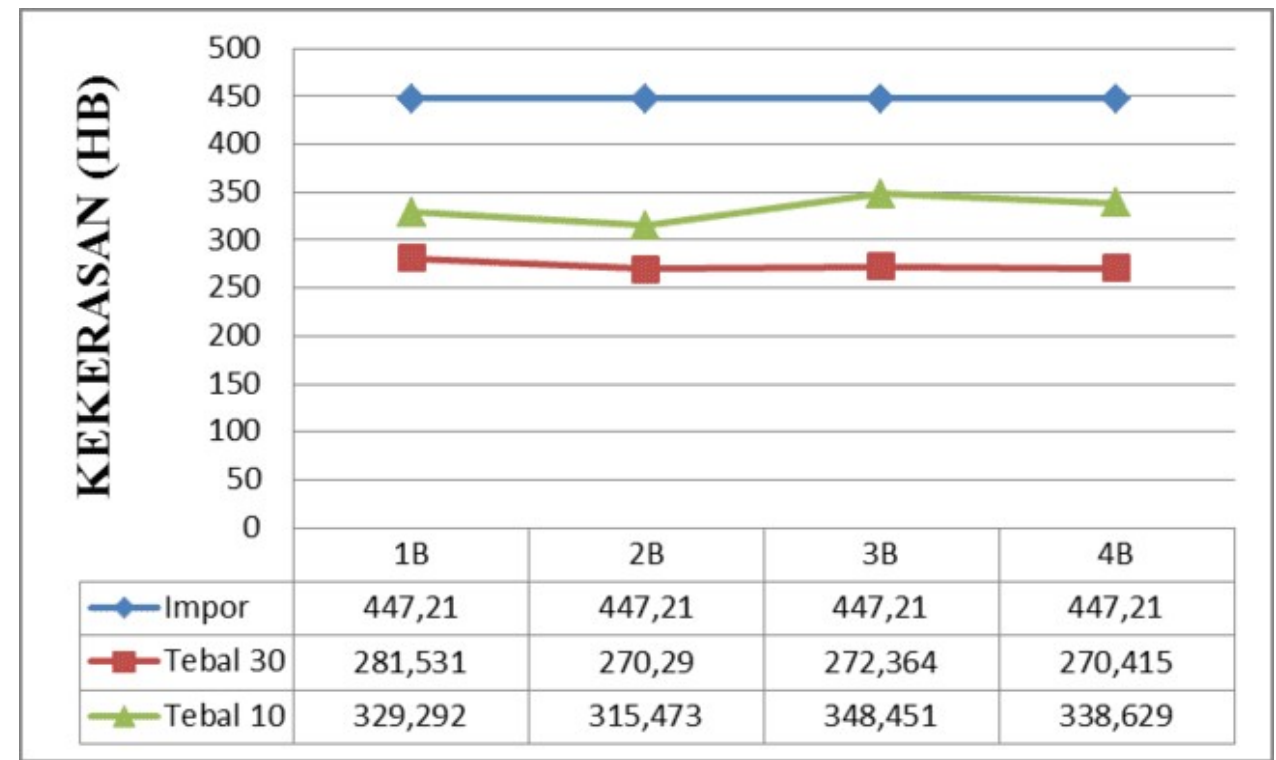

Gambar 9. Grafik Perbandingan Harga Kekerasan Tebal 10 mm VS 30 mm

Gambar 9 memperlihatkan perbandingan harga kekerasan hasil pengujina kekerasan pada spesimen hasil pengecoran dan harga kekerasan dari spesimen bahan impor. Pada grafik tersebut dapat dilihat perbedaan harga kekerasan dengan spesimen dengan ketebalan $30 \mathrm{~mm}$ dan spesimen dengan ketebalan $10 \mathrm{~mm}$. pengujian kekerasan yang dilakukan menunjukkan bahwa harga kekerasan rata-rata tertinggi pada specimen dengan ketebalan $30 \mathrm{~mm}$ adalah sebesar 281,531 HB dan harga kekerasan rata-rata tertinggi untuk spesimen dengan ketebalan $10 \mathrm{~mm}$ mencapai $348,451 \mathrm{HB}$. Hal ini terjadi karena pada spesimen dengan ketebalan yang lebih kecil (lebih tipis) memiliki fasa perlit. Hal ini sesuai dengan hasil dari anailisa struktur mikro, dimana struktur perlit serta karbida menjadi bertambah banyak dan rapat, seperti yang terlihat pada gambar 11, gambar 12, gambar 13, gambar 14, gambar 15, gambar 16, gambar 17, gambar 18.

Jika dibandingkan dengan bahan impor, maka harga kekerasan dari bahan untuk ball mill yang dibuat dengan proses pengecoran dalam penelitian ini belum mampu mencapai harga kekerasan dari bahan impor

\subsection{Hasil Pengujian Uji Impak}

Hasil uji impak dari spesimen hasil pengecoran dan spesimen dari bahan impor terlihat pada gambar 10. Grafik pada gambar 10 memperlihatkan bahwa terdapat harga impak dari specimen hasil pengcoran yang mampu menyamai harga impak dari bahan impor yaitu sebesar $4,76 \mathrm{~J} / \mathrm{mm}^{2}$. 


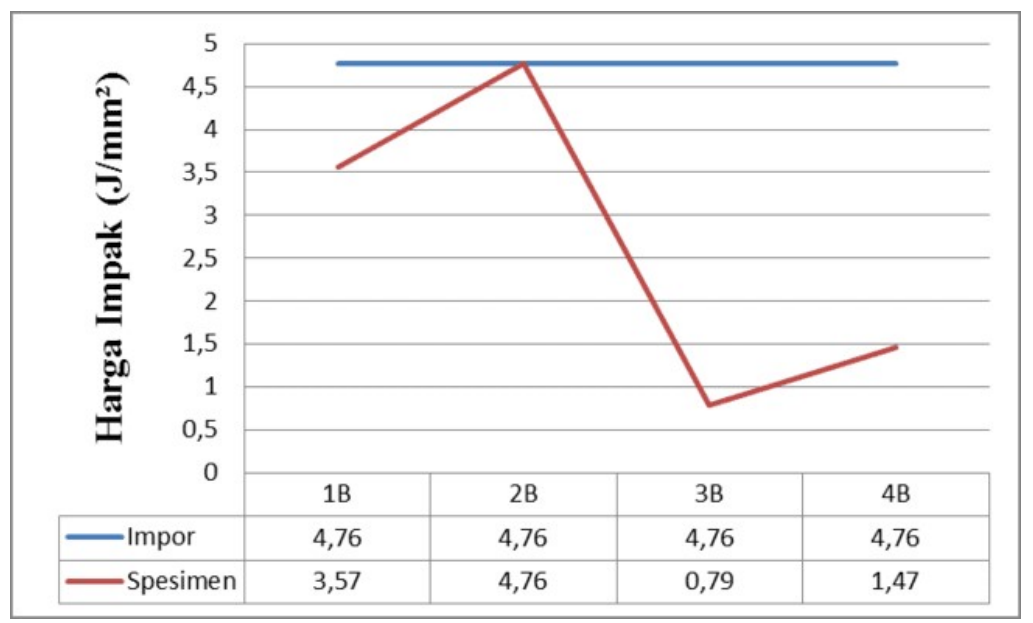

\section{Gambar 10. Grafik Perbandingan Harga Impak Titik Spesimen VS Spesimen Impor}

\subsection{Hasil Pengujian Struktur Mikro}

Pengujian struktur mikro ini dilakukan paling akhir, yaitu setelah pengujian kekerasan dan pengujian impak. Proses pengujian struktur mikro ini dilakukan untuk melihat bentuk struktur dan fasa dari material hasil pengecoran white cast iron. Bentuk struktur dan fasa material sangat erat kaitannya dengan sifat mekanik dari material. Struktur mikro yang terlihat pada material akan menjadi bukti penguat bagi sifat mekanik yang dimiliki olehh suatu material. Hasil dari uji analisis struktur mikro terilhat pada gambar 11, gambar 12, gambar 13, gambar 14, gambar 15, gambar 16, gambar 17, dan gambar 18.

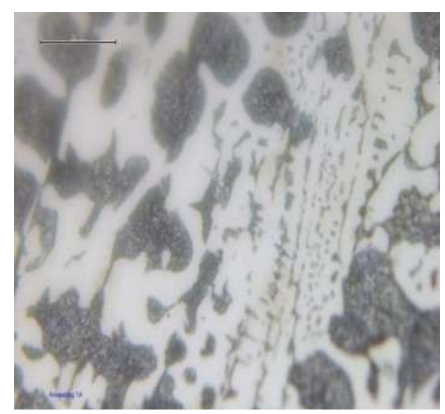

Gambar 11. Hasil Uji ASM Tebal 10 mm (Inokulan)

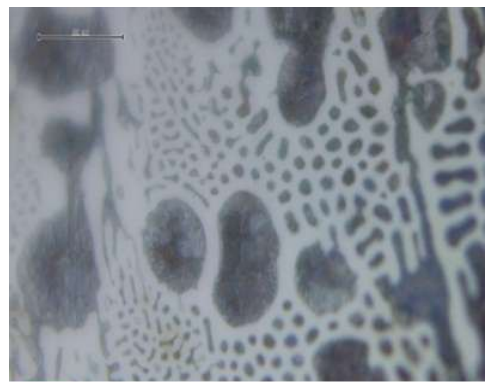

Gambar 13. Hasil Uji ASM Tebal 10 mm (Non Inokulan)

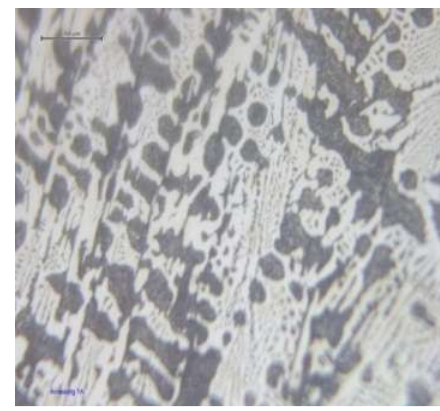

Gambar 12. Hasil Uji ASM Tebal 30 mm (Inokulan)

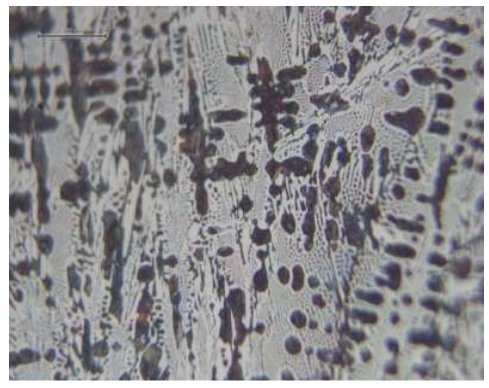

Gambar 14. Hasil Uji ASM Tebal 30 mm (Non Inokulan) 


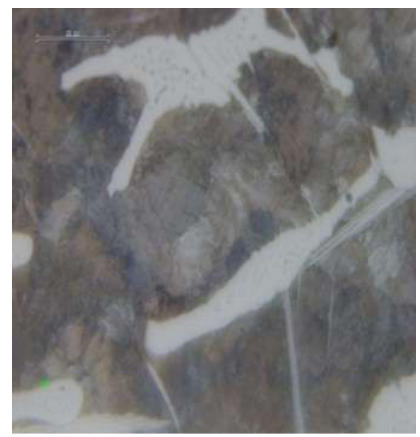

Gambar 15. Hasil Uji ASM Tebal 10 mm (Inokulan)

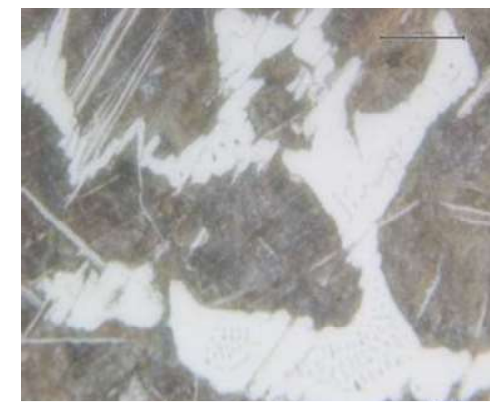

Gambar 17. Hasil Uji ASM Tebal 10 mm (Non Inokulan)

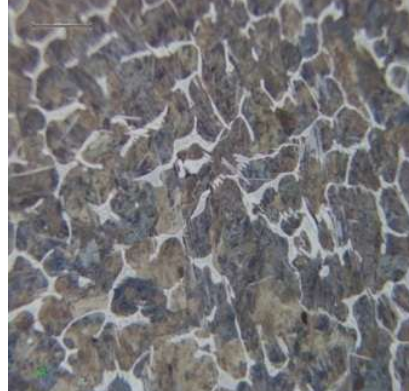

Gambar 16. Hasil Uji ASM Tebal 30 mm (Inokulan)

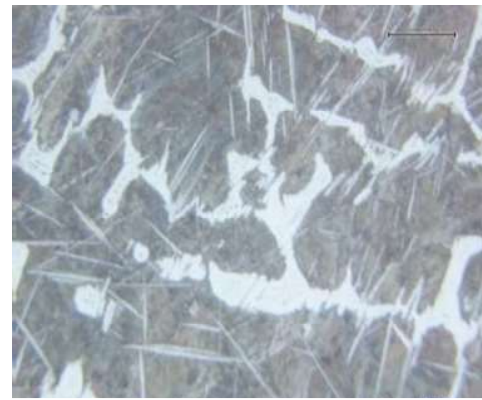

Gambar 18. Hasil Uji ASM Tebal 30 mm (Non Inokulan)

Pada gambar diatas dapat dilihat bahawa hasil uji ASM untuk material yang dicampur inkulan lebih terlihat terdapat karbida berwarna putih, austenit berwarna titik hitam, dan titik hitam austenit akan berubah menjadi martensit seiring terjadinya proses abrasive sehingga akan menghasilka sifat kekerasan yang tinggi.

\section{Kesimpulan dan Saran}

\subsection{Kesimpulan}

Kesimpulan yang didapatkan dari penelitian yang telah di lakukan adalah sebagai berikut:

- Untuk saat ini material white cast iron low $\mathrm{Cr}$ and low Ni yang diteliti tidak memenuhi persayaratan karena nilai kekerasannya masih di bawah bahan impor.

- Untuk meningkatkan kekerasan harus dilakukan proses lanjut dengan perlakuan panas agar harga kekerasannya meningkat.

- Dari hasil yang sudah didapatkan, diketahui bahwa ketebalan sangat berpengaruh terhadap kekerasan, yang mana semakin tipis ketebalannya maka harga kekerasannya semakin tinggi.

\subsection{Saran}

Penelitian ini diharapkan bisa dilakukan ke tahap selanjutnya, yaitu dari segi peningkatan kekerasan sehingga dapat memenuhi nilai standar yang dipersyaratkan untuk produksi grinding ball di dalam negeri dengan kualitas baik dan harga yang murah. Hal ini sangat penting untuk dicapai agar perusahaan semen di Indonesia tidak lagi melakukan impor bahan untuk membuat grinding ball. 


\section{DAFTAR RUJUKAN}

[1] Adam, K. (2011). Faktor Perpatahan dan kelelahan pada kekuatan bahan material. ILTEK. Volume 6. Nomor 12.

[2] Ditter, G.E.(1993). Metalurgi Mekanik. (jilid I dan 2), Erlangga, Jakarta.

[3] Irwan, Y. (2016). Material Teknik. Jurusan Teknik Mesin. Institut Teknologi Nasional. Bandung

[4] Shofi, A. (2013). Karakteristik Struktur Mikro dan Sifat Mekanik Besi Tuang Putih Paduan Krom Tinggi Hasil Thermal Hardening Untuk Aplikasi Grinding Ball. LIPI. Lampung

[5] Sumirat, U. (2020). Pengembangan Material Grinding Ball Pada Ball Mill Yang Terbuat Dari White Cast Iron dan Diaplikasikan Pada Pabrik Semen. Institut Teknologi Nasional. Bandung

[6] Surojo, E. (2012). Studi Pengaruh Komposisi Kimia dan Ketebalan Coran Terhadap Struktur Mikro Besi Cor Pada Kasus Pembuatan Besi Cor Vermicular. Jurusan Teknik Mesin. Universitas Sebelas Maret. Surakarta. 